\title{
Investigating Frequency and Distribution of Transition Markers in English and Persian Research Articles in Applied Linguistics: Focusing on Their Introduction Sections
}

\author{
Leila Bahrami \\ Islamic Azad University, Mobarakeh Branch, Isfahan, Iran \\ Email: lbahrami08@gmail.com
}

\begin{abstract}
The pressure to produce work in English and to publish internationally has increased over recent years. However, a large number of non-native writers may be excluded from the web of global scholarship due to defective rhetorical organizations and discourse structures of their works. This study aimed to investigate frequency and distribution of transition markers (TMs) in introduction sections of applied linguistics research articles (RAs) written by native writers of English (NE), non- native Persian writers of English (NNE), and native writers of Persian (NP). For this purpose, 45 RAs were functionally and manually analyzed and compared to find possible differences among their introduction sections in terms of frequency and distribution of TMs. The results showed that compared with English, Persian language makes more use of TMs. Moreover, it was revealed that NNE writers show a pattern of overuse of TMs when they write in English owing to the effects of their native language writing culture.
\end{abstract}

Index Terms - research article, introduction section, applied linguistics, metadiscourse, transition markers

\section{INTRODUCTION}

There is no doubt that English is the world's predominant language of research and scholarship. That is, English is the lingua franca of academic discourse and as Vold (2006) notes, novices as well as established researchers must be able to express themselves in English if they want to be fully accepted members of the international academic community. In other words, academic writers need to be aware of the rhetorical conventions used by professionals in the community in order to enter and to join the academic world (Swales, 1990).

In today's flooded world with information, publication is considerably appreciated in hiring, promotion and continued employment (Belcher, 2007). As a result, many non-native writers have recently shown a stronger tendency to join their disciplinary communities through writing research articles. However, a large number of non-native writers may be excluded from the web of global scholarship (Hyland, 2006) mostly due to problems with rhetorical organizations and discourse structures in their writings.

It is commonly assumed that writers' introductions are crucial to the success of their texts. Writing effective introductions that can both get the interest of the readers and justify the way the research addresses an important gap in a specific field is of special significance in the highly competitive world of academic publication nowadays. An appealing introduction should fulfill two basic functions of getting the interest of the readers and also justifying the way the research addresses an important gap in a specific field (Ya-jun, 2009). Thus, particular attention has been paid to the study of introductions and how they are organized in recent years.

However, writing a winsome introduction that helps shape readers' first impression is considered to be troublesome for many academic writers. This is particularly true when the writer has to make at least four decisions to ensure the effectiveness of the introduction. These decisions include appropriate amount and type of background knowledge, the writers' stance towards the readers and previous scholarship, the winsomeness of the appeal, and the directness of the approach (Swales, 1990). Academics, thus, have to gain fluency in the rhetorical conventions of English language discourse to become or remain a member of the international academic community, to understand their discipline, to establish their careers, and to successfully navigate their learning (Hyland, 2006).

A key to effective text production is conscious awareness of the rules and conventions of rhetorical functions of the target language (Faghih \& Rahimpour, 2009). One aspect of such awareness is metadiscourse awareness. Since metadiscourse is an integral part of academic discourse and of particular importance at advanced levels of academic writing, there seems to be a crucial need for studies that investigate metadiscourse in research articles, particularly in introduction section of the articles because introductions determine the winsomeness of the articles to a large extent.

Hyland (2005, p. 37) defines metadiscourse as "The cover term for the self-reflective expressions used to negotiate interactional meanings in a text, assist the writer (or speaker) to express a viewpoint and engage with readers as 
members of a particular community." A number of taxonomies of metadiscourse have been proposed since its emergence. Some of the major models of metadiscourse markers are Vande Kopple (1985), Crismore and Steffensen (1993), Hyland and Tse (2004), and Adel (2006). Most of the models organize metadiscourse markers under the labels of textual and interpersonal. Textual metadiscourse refers to the organization of discourse and interpersonal metadiscourse reflects the writer's attitude toward the content and the audience. Hyland and Tse (2004) propose an interpersonal model of metadiscourse believing that all metadiscourse resources are interpersonal and organize the metadiscourse resources under the headings of interactive (instead of textual) and interactional (instead of interpersonal) metadiscourse.

Interactive resources refer to those features of the text which set out an argument to explicitly establish the writer's preferred interpretations. These features are used to organize prepositional information in the ways that the audience finds the text coherent and convincing (Hyland \& Tse, 2004). Table 1 summarizes Hyland and Tse's interpersonal model of metadiscourse.

Transitions as one of the most widely used interactive metadiscourse resources (Burneikaite, 2009) are used to arrange propositions in the text and involve the readers. According to Hyland (2005), transition markers are mainly conjunctions and adverbial phrases which help readers interpret pragmatic connections between steps in an argument by marking additive, contrastive, and causative steps in the discourse. Addition adds elements to the argument and consists of items such as and, furthermore, moreover, and etc. Comparison marks arguments as either similar (e.g., similarly, likewise, equally, correspondingly, and etc.) or different (e.g., in contrast, however, but, on the contrary, on the other hand, and etc.). Consequence relations tell readers that either a conclusion is being drawn or justified (e.g., therefore, consequently, in conclusion, and etc.) or an argument is being countered (e.g., admittedly, nevertheless, anyway, in case, of course, and etc.).

Although there are several studies that compare metadiscourse use in English and Persian research articles (Vassileva, 2001; Abdi, 2002; Dahl, 2004; Zarei \& Mansoori, 2007; Farrokhi \& Ashrafi, 2009; Shokouhi \& Talati Baghsiahi, 2009; Abdi, Tavangar, \& Tavakoli, 2010; Rashidi \& Souzandehfar, 2010), up to this point, analysis of introduction sections of research articles in terms of the frequency and distribution of interactive metadiscourse resources has received little attention. This study aims to explore and gain insights into the way transitions, as a subcategory of interactive resources, are distributed in introduction sections of research articles in Persian and English.

\section{REVIEW OF LITERATURE}

Distribution and use of metadiscourse in research articles has been demonstrated in a number of contrastive and descriptive studies in recent years (Vassileva, 2001; Abdi, 2002; Dahl, 2004; Zarei \& Mansoori, 2007; Farrokhi \& Ashrafi, 2009; Shokouhi \& Talati Baghsiahi, 2009; Abdi, et al., 2010; Rashidi \& Souzandehfar, 2010).

In order to see whether language or discipline is the most important variable governing the pattern of metatext in academic discourse, Dahl (2004) investigates writer manifestation in research articles in three languages, English, French, and Norwegian, and three disciplines, economics, linguistics, and medicine. The findings suggest that in medical texts, metatext is a marker of academic discipline whereas in economics and linguistics texts, language and national writing traditions seem to be much more influential.

In addition, Zarei and Mansoori (2007) compare and contrast the use of metadiscourse elements in Persian and English research articles to find out how English and Persian make use of metadiscourse elements, and whether the two languages differ in using metadiscourse resources in academic texts. By analyzing 19 articles in the two languages, they conclude that both Persian and English used interactive resources more than interactional ones, emphasizing the significance of text coherence over interpersonal function of language in the academic genre. They also indicate that compared with English, Persian capitalizes on more interactive resources.

Shokouhi and Talati Baghsiahi (2009), furthermore, investigate metadiscourse functions in sociology research articles in Persian and English. The results reveal a higher number of metadiscourse elements in the English texts. It is further found that the frequency of textual metadiscourse markers is greater than the interpersonal markers in both language samples and among the different metadiscourse elements, text connectors are employed more frequently in both languages. They finally conclude that the Persian writers are less likely interested in explicitly organizing the texts and orienting the readers.

The studies reviewed indicate that metadiscourse as a rhetorical means in research articles is culture-bound. To date, studies have revealed significant differences in the use of metadiscourse resources across Persian and English. However, a lack of studies that analyze introduction sections of research articles in terms of metadiscourse use is quite obvious in the field. This work is an attempt to cast light on the issue of metadiscourse use across introduction sections of Persian and English research articles.

\section{METHOD}

\section{A. The Corpora}

A number of criteria were utilized for the selection of the 3 corpora in this study. First of all, three criteria of genre, ESP, and text type proposed by Grabe (1987) were utilized. Research articles were chosen to meet the genre criterion 
and they were also limited to the field of applied linguistics to meet the ESP criterion. Furthermore, among the moves 'introduction' section was singled out in order to guarantee the text type criterion. Second, to take care of the time factor, all texts were chosen from among articles published in 2009 issues of the intended journals. Third, in order to choose articles written by native English writers, it was attempted to choose articles that had at least one English nativespeaker author judged by the names and affiliations of the authors. Fourth, caution was taken to choose the articles which had separate introduction section.

The data for this study comprise a total of 45 English research article introduction sections in applied linguistics, 15 written by native writers of English published in 2009 issues of the Applied Linguistics, English for Specific Purposes, and the Journal of Pragmatics, 5 articles from each of which (See Appendix A), 15 by non- native Persian writers of English published in 2009 issues of the Pazhuhesh-e Zabanha-ye Khareji (Foreign Language Studies) journal published by University of Tehran, Journal of English Language Teaching and Learning published by University of Tabriz, and the Iranian journal of Applied Language Studies published by University of Sistan and Baluchestan, 6,6, and 3 articles from each, respectively (See Appendix B), and 15 by native writers of Persian published in 2009 issues of Pazhuhesh-e Zabanha-ye Khareji ( Foreign Language Studies) journal, 13 from the journal published by University of Tehran and the other two from that published by University of Tabriz (See Appendix C).

\section{B. The Analysis}

According to Ädel (2006) metadiscursive expressions can be multifunctional and context dependent, therefore the propositions containing metadiscourse markers were identified functionally and manually throughout each corpus. Furthermore, headings, footnotes, quotes, equations, linguistic examples, tables and figures which appeared in the introduction sections of the articles were excluded from the data in order to analyze the corpora. Since the total number of words varied in each corpus, NE: 15321, NP: 16017, and NNE: 15206, the frequency of transition markers was calculated per 1000 words.

\section{RESULTS AND DISCUSSION}

One of the main objectives of this study was to examine the occurrence of transition markers in introduction sections of research articles in applied linguistics written by native writers of English, non- native Persian writers of English, and native writers of Persian. Another aim was to identify the differences between native and non-native writers of English in the use of transition markers in introduction sections of the articles. In order to meet these goals, the articles were examined functionally and manually to determine the frequency of these words. Table 2 summarizes the results of the analysis; the raw number of occurrences of the transition markers and also their frequency per 1000 words in the 3 corpora are presented in this table.

As table 2 indicates, among the 3 categories of transition markers, additive markers show the highest and causative markers show the lowest frequencies in each corpus. However, there exist some differences in the pattern of distribution of the 3 categories of transition markers across the 3 corpora, For example, addition and consequence markers show the highest frequency per 1000 (i.e., 32.09 and 2.37, respectively) in the NP corpus, while comparison markers show the highest frequency per 1000 words (i.e., 7.70) in the NE corpus. The total frequencies also show that NP writers made the most use of the transition markers (37.64 per 1000 words) compared to NE writers (34.98 per 1000 words) and NNE writers (37.82 per 1000 words). It shows that Persian puts more emphasis on text coherence and organization. These findings are in line with the findings of Zarei and Mansoori (2007) which indicate that compared with English, Persian capitalizes on more interactive resources.

Furthermore, comparing the total frequencies in the NNE corpus with those in the NP corpus and also with those in the NE corpus reveals that due to the effects of the Persian language writing conventions, non- native Persian writers of English generally show a pattern of overuse in the application of transition markers. Likewise, Farrokhi and Ashrafi (2009) conclude that there is a significant difference in the distribution of textual metadiscourse markers between the writings of native English writers and non-native Persian writers of English. Findings of this study also provide further evidence for Dahl's 2004 claim that language and national writing traditions seem to be the most influential factors in using interactive metadiscourse markers in linguistics texts. These finding also support Kaplan's 1966 indication that the influence of linguistic background and cultural traditions of non- native writers in English persists even when EFL writers attain a good command of a target language. Figure 1 summarizes these results:

Writing research articles is considered to be a troublesome and complicated task particularly for the non-native writers of English because it requires not only mastering the explicit linguistic rules and the genre schemata of the discipline, but also understanding of higher levels of discourse. Furthermore, the influence of linguistic background and cultural traditions of non- native writers in English adds to the complexity of the task. Results of the present study revealed that Persian EFL writers of English preserve the writing conventions of Persian especially when using addition and consequence markers. Therefore, introducing EFL learners to the practice of professional native writers can provide them with rhetorical knowledge and understanding of the ways meanings are conveyed in their disciplines. Moreover, the results of this study could be useful to foreign language writers, particularly Persian EFL writers who seek to write publishable articles in international journals. These findings further can be a guide for teaching and understanding of cross-cultural academic writing. The results of this study also can be used to benefit research in contrastive rhetoric. 


\section{CONCLUSION}

This study aimed to examine the occurrence of transition markers in introduction sections of research articles in applied linguistics written by native writers of English, non- native Persian writers of English, and native writers of Persian and further to identify the differences between native and non-native writers of English in terms of the use of transition markers in introduction sections of the articles.

The results of this study suggest that compared with English, Persian capitalizes on more interactive resources. It was further revealed that the use of interactive matadiscourse resources is regulated more or less by the conventions of native language writing culture rather than by the disciplinary culture among non- native Persian writers of English.

Since interactive metadiscourse resources particularly, transition markers are central to the coherence and organization of research articles and help readers interpret pragmatic connections between steps in an argument, Iranian EFL writers need to deepen their understanding of the disciplinary conventions regulating the use of metadiscourse resources in order to write internationally publishable articles.

Lack of familiarity with the conventions of disciplinary culture may cause difficulties for those non-native writers who want to be considered as a member of disciplinary community. Therefore, EFL writers need to increase awareness of rhetorical conventions of their disciplinary community to enter and to join that community.

This study was limited to the analysis of the use of transition markers in introduction sections of research articles in applied linguistics and took into account only cross-language differences. Future studies could explore the use of other categories of interactive and interactional metadiscourse resources in other sections of research articles such as abstract, method, results, discussion, and conclusion. Moreover, further research needs to be conducted to include possible differences across other academic genre and disciplines.

\section{APPENDIX A}

List of the English Research Articles Used as the NE Corpus (The articles have been alphabetically ordered based on the author (s)' names.)

Borg, S. (2009). English Language Teachers' Conceptions of Research. Applied Linguistics, 30(3), 358-388.

Drewa, P. \& Walker, T. (2009). Going too far: Complaining, escalating and disaffiliation. Journal of Pragmatics, 41, 2400-2414.

Durrant, P. (2009). Investigating the viability of a collocation list for students of English for academic purposes. English for Specific Purposes. 28, 157-169.

Ellis, R. (2009). The differential effects of three types of task planning on the fluency, complexity, and accuracy in 12 oral production. Applied Linguistics, 30(4),474-509.

Escalera, E. A. (2009). Gender differences in children's use of discourse markers: Separate worlds or different contexts?. Journal of Pragmatics, 41, 2479-2495.

Harwood, N. (2009). An interview-based study of the functions of citations in academic writing across two disciplines. Journal of Pragmatics, 41, 497-518.

Hellermann, J. \& Cole, E. (2009). Practices for social interaction in the language-learning classroom: Disengagements from dyadic task interaction. Applied Linguistics, 30(2), 186-215.

Hinkel, E. (2009). The effects of essay topics on modal verb uses in L1 and L2 academic writing. Journal of Pragmatics, 41, 667-683.

Mills, S. (2009). Impoliteness in a cultural context. Journal of Pragmatics, 41, 1047-1060.

Morton, J. (2009). Genre and disciplinary competence: A case study of contextualization in an academic speech genre. English for Specific Purposes. 28, 217-229

Norris, J. M. \& Ortega. L (2009). Towards an organic approach to investigating CAF in instructed SLA: The case of complexity. Applied Linguistics, 30(4), 555- 578.

Skehan, P. (2009). Modelling second language performance: integrating complexity, accuracy, fluency, and lexis. Applied Linguistics, 30(4), 510-532

Sheldon, E. (2009). From one I to another: Discursive construction of self-representation in English and Castilian Spanish research articles. English for Specific Purposes. 28, 251-265.

Webb, S. \& Rodgers, M. P. H. (2009). The lexical coverage of movies. Applied Linguistics, 30(3),407-427.

Wua, H. D. \& Badger, R. G. (2009). In a strange and uncharted land: ESP teachers' strategies for dealing with unpredicted problems in subject knowledge during class. English for Specific Purposes. 28, 19-32.

Wulff, S. , Swales, J. M. \& Keller, K. (2009). "We have about seven minutes for questions": The discussion sessions from a specialized conference. English for Specific Purposes. 28, 79-92.

\section{APPENDIX B}

List of the English Research Articles Used as the NNE Corpus (The articles have been alphabetically ordered based on the author (s)' names.)

Abdi, R. (2009). Projecting cultural identity through metadiscourse marking: A comparison of Persian and English research articles. Journal of English Language Teaching and Learning, 212, 1- 15. 
Atai, M. R. \& Soleimany, M. (2009). On the effect of text authenticity \& genre on EFL learners' performance in CTests. Pazhuhesh-e Zabanha-ye Khareji, 49, 109- 123.

Baleghizadeh, S. \& Farshchi, S. (2009). An exploration of teachers' beliefs about the role of grammar in iranian high schools and private language institutes. Journal of English Language Teaching and Learning, 212, 17- 38.

Farrokhi, F. \& Ashrafi, S. (2009). Textual metadiscourse resources in research articles. Journal of English Language Teaching and Learning, 212, 39- 75.

Ghazanfari, M. (2009). The role of visualization in EFL learners' reading comprehension and recall of short stories. Iranian journal of Applied Language Studies, 1(1), 1- 23.

Hashemi,.M. R., Khodadadi, E. \& Yazdanmehr, E. (2009). Learners' evaluation of EFL writing tasks in Iran's ESOL exam preparation coursess. Journal of English Language Teaching and Learning, 212, 77- 106.

Khajeh, Z. (2009). Transmission of ideology through translation: A critical discourse analysis of Chomsky's "media control" and its Persian translations. Iranian journal of Applied Language Studies, 1(1), 24- 42.

Khomeijani Farahani, A.A. \& Khaghani Nejad, M. S. (2009). A study of task-based approach: The effects of taskbased techniques, gender, and different levels of language proficiency on speaking development. Pazhuhesh-e Zabanha-ye Khareji, 49, 23-41.

Moini, M. R. (2009). The impact of EFL teachers' cognition on teaching foreign language grammar. Pazhuhesh-e Zabanha-ye Khareji, 49, 141- 164.

Rabi, A. (2009). Of Relating the linguistic description to an interpretation of a literary work (poetry) . Iranian journal of Applied Language Studies, 1(1), 100- 114.

Rezaee, A. A. Sayfouri, N. (2009). Iranian ISI and non-ISI medical research articles in English: A comparative ESP/EAP move analysis. Journal of English Language Teaching and Learning, 212, 135- 160.

Samar, R. G. \& Shayestefar, P. (2009). Corrective feedback in EFL classrooms: Learner negotiation strategies and uptake. Journal of English Language Teaching and Learning, 212, 107- 134.

Talebinezhad, M. R. \& Mousapour Negari, G. (2009). The effect of explicit teaching of concept mapping in expository writing on efl students' self-regulation. Pazhuhesh-e Zabanha-ye Khareji, 49, 85- 108.

Zare-ee, A. (2009). The effects of teaching genre moves on EFL learners' performance in letter writing. Pazhuhesh-e Zabanha-ye Khareji, 49, 43- 64.

Zarei, A. A. (2009). The effect of bimodal, standard, and reversed subtitling on L2 vocabulary recognition and recall. Pazhuhesh-e Zabanha-ye Khareji, 49, 65-85.

\section{APPENDIX C}

List of the Persian Research Articles Used as the NP Corpus (The articles have been alphabetically ordered based on the author (s)' names.)

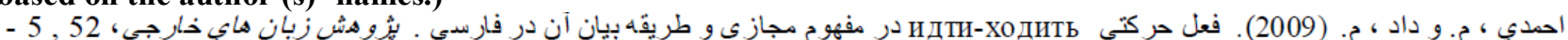

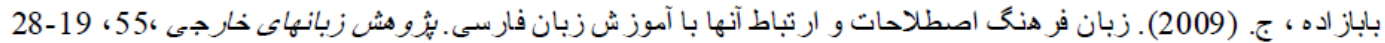

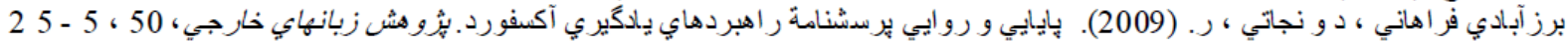

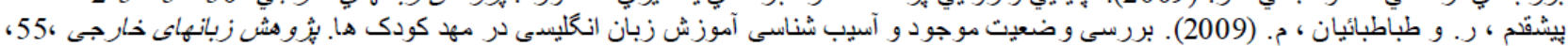

$$
\begin{aligned}
& \text { 69- } 55 \\
& \text { بهلو ان نز اد ، م. و اصطهيجانتى ، ل. (2009). بررسى كنش هاي كفتار در سخنر انى هاي روساي جمهور ايران و آمريكا شهريور } 1385 \text { ، سازمان }
\end{aligned}
$$

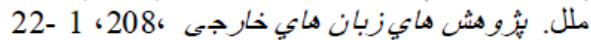

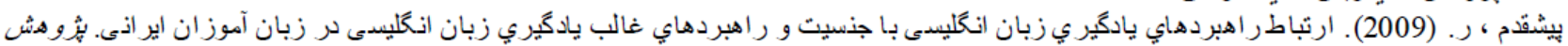

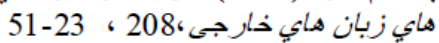

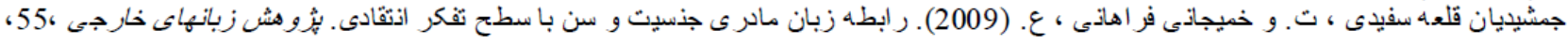

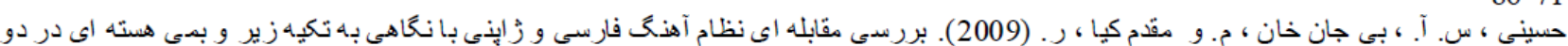

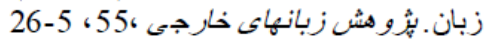

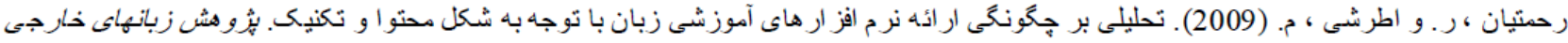

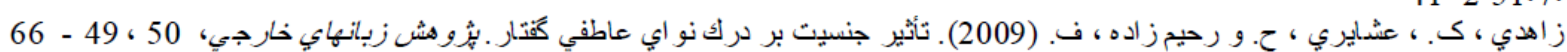

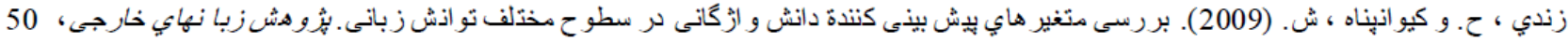

$$
\begin{aligned}
& 81-67 \text { ، }
\end{aligned}
$$


TABLE1

A Model of METAdisCOURSE In ACADEMIC TEXTS (HYLAND AND TSE, 2004, P. 169)

\begin{tabular}{|l|l|l|}
\hline \multicolumn{1}{|c|}{ Category } & \multicolumn{1}{|c|}{ Functions } & \multicolumn{1}{c|}{ Examples } \\
\hline Interactive & Help to guide the reader through the text & Resources \\
Transitions & express relations between main clauses & in addition; but; thus; and \\
Frame markers & refer to discourse acts, sequences or stages & refer to informatly; to conclude; my purpose is \\
Endophoric markers & refer to information from other texts & noted above; see figure; in section 2 \\
Evidentials & elaborate propositional meaning & namely; e.g.; such as; in other words \\
Code glosses & Involve the reader in the text & Resources \\
\hline Interactional & withhold commitment and open dialogue & might; perhaps; possible; about \\
Hedges & emphasize certainty and close dialogue & unfort definitely; it is clear that \\
Boosters & expresses writers' attitude to proposition & I; we; my; me; our \\
Attitude markers & explicit reference to author(s) & consider; note; you can see that \\
Self-mentions & explicitly build relationship with reader &
\end{tabular}

TABLE 2

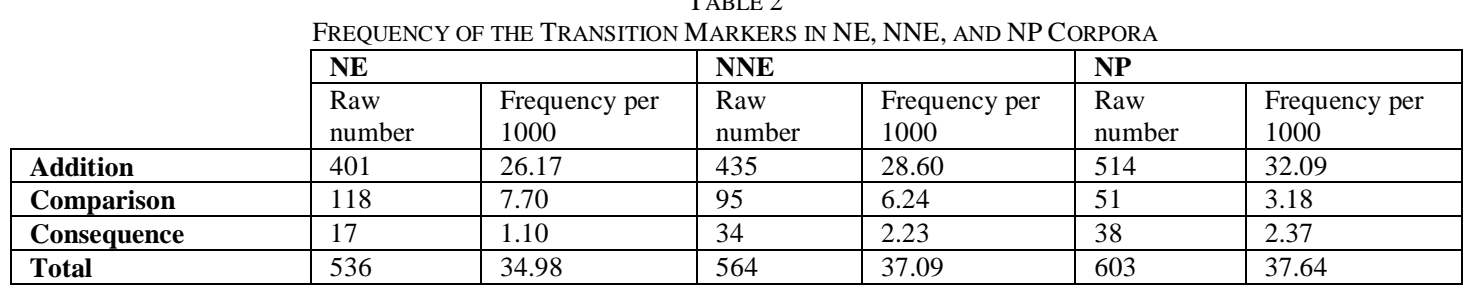

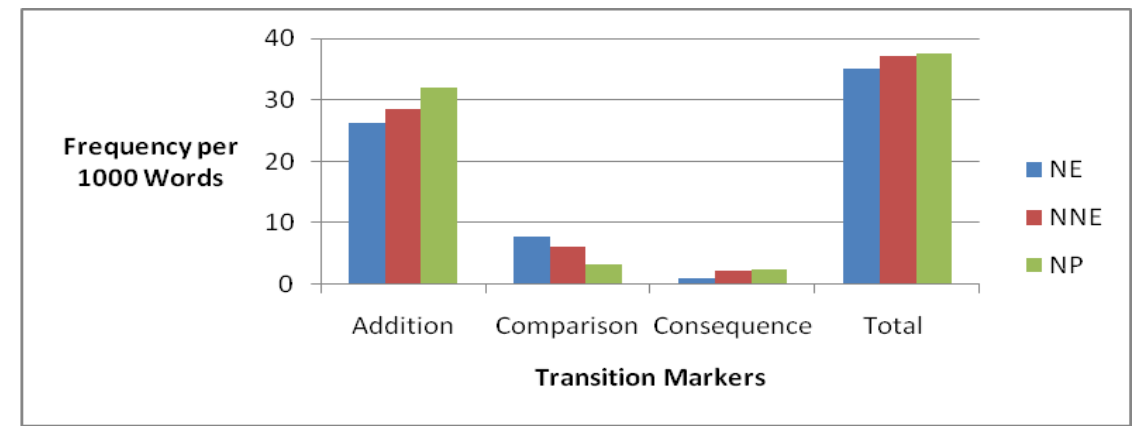

Figure 1. Frequency of the transition markers in NE, NNE, and NP corpora.

\section{REFERENCES}

[1] Abdi, R. (2002). Interpersonal metadiscourse: An indicator of interaction and identity. Discourse Studies. 4(2), 139-145.

[2] Abdi, R., Tavangar Rizi, M., \& Tavakoli, M. (2010). The cooperative principle in discourse communities and genres: A framework for the use of metadiscourse. Journal of Pragmatics. 42(6), 1669-1679.

[3] Ädel, A. (2006). Metadiscourse in L1 and L2 English. Philadel phia: John Benjamins.

[4] Belcher, D. D. (2007). Seeking acceptance in an English-only research world. Journal of Second Language Writing. 16, 1-22.

[5] Burneikaite, N. (2009). Metadiscoursal connectors in linguistics MA theses in English L1 \& L2. KALBOTYRA. 61(3), 36-50.

[6] Crismore, A., Markkanen, R., \& Steffensen, M. (1993). Metadiscourse in persuasive writing: A study of texts written by American and Finnish university students. Written Communication. 10(1), 39-71.

[7] Dahl, T. (2004). Textual metadiscourse in research articles: A marker of national culture or of academic discipline?. Journal of Pragmatics. 36, 1807-1825.

[8] Faghih, E. \& Rahimpour, S. (2009). Contrastive rhetoric of English and Persian written texts: Metadiscourse in applied linguistics research articles. Rice Working Papers in Linguistics. 1,92- 107.

[9] Farrokhi, F. \& Ashrafi, S. (2009). Textual metadiscourse resources in research articles. Journal of English Language Teaching and Learning. 212, 39-75.

[10] Grabe, W. (1987). 'Contrastive Rhetoric and Text Type Research', in U. Connor and R. B. Kaplan (1996). (eds) Writing across Languages: Analysis of L2 Texts. Redwood, CA: Addison-Wesley.

[11] Hyland, K. (2005). Metadiscourse: Exploring interaction in writing. London: Continuum.

[12] Hyland, K. (2006). English for academic purposes. London and NewYork: Routledge.

[13] Hyland, K., \& Tse, P. (2004). Metadiscourse in academic writing: A reappraisal. Applied Linguistics. 25(2), $156-177$.

[14] Kaplan, R.B. (1966). Cultural thought pattern in intercultural communication. Journal of Language Learning. 1(1), 1-20.

[15] Rashidi, N. \& Souzandehfar, M. (2010). Text-organizing metatext in research articles: An English-Persian contrastive analysis. TESL-EJ.13 (4).

[16] Shokouhi, H. \& Talati Baghsiahi, A. (2009). Metadiscourse functions in English and Persian sociology articles: A study in contrastive rhetoric. Poznań Studies in Contemporary Linguistics. 45(4), 549-568.

[17] Swales, J. (1990).Genre analysis: English in academic and research settings. Cambridge: Cambridge University Press.

[18] Vande Kopple, W. J. (1997). Refining and applying views of metadiscourse. Paper presented at the 48th Annual Meeting of the Conference on College Composition and Communication, Phoenix, Arizona, USA. 
[19] Vassileva, I. (2001). Commitment and detachment in English and Bulgarian academic writing. English for Specific Purposes. 20, 83-102.

[20] Vold, E. T. (2006). Epistemic modality markers in research articles: A cross-linguistic and cross-disciplinary study. International Journal of Applied Linguistics. 16 (1), 61 - 87.

[21] Ya-jun, Z. (2009). CARS model in analyzing the introduction of research articles: An example from the field of sports science and medicine. US-China Foreign Language. 7(3), 61- 65.

[22] Zarei, G. R., \& Mansoori, S. (2007). Metadiscourse in Academic Prose: A contrastive analysis of English and Persian research articles. The Asian ESP Journal. 3(2), 24-40.

Leila Bahrami, MA. in TEFL from the University of Isfahan, Iran. She is currently teaching English to Persian EFL students. Her research interests are writing instruction and genre analysis. 